$103 \mid$ InterAção

\title{
O MITO DE JANO: AS DUAS FACES DA ORDEM PÚBLICA NO DIREITO INTERNACIONAL PRIVADO
}

\author{
Pedro Henrique de Faria Barbosa ${ }^{1}$
}

Sylvio Loreto ${ }^{2}$

\section{Resumo}

O presente artigo insere-se no campo de estudo do Direito Internacional Privado, focando-se na análise da atual natureza da ordem pública. Seu objetivo principal é a análise das ordens públicas nacional e internacional, considerando se as mesmas são conceitos excludentes ou convergentes. Tal abordagem é desenvolvida por meio de uma interpretação metafórica da conexão entre os conceitos de ordem pública e o mito da divindade romana Janos. Primeiramente, é feita uma análise acerca da formulação do conceito de ordem pública nacional num âmbito jurídico-histórico, considerando as definições legais trazidas nas normas internacionais e nacionais. Em seguida, versa sobre a possibilidade de conceituação de uma ordem pública internacional e quais seriam as fontes da mesma. Este estudo aponta para conclusões no sentido da necessidade de interpretações que garantam a coexistência entre as duas modalidades de ordem pública e a garantia do respeito ao Direito Internacional Privado e aos direitos nacionais.

Palavras-chave: Direito Internacional Privado. Ordem Pública Nacional. Ordem Pública Internacional. Jano. UNCITRAL.

\begin{abstract}
The present article is inserted in the field of study of private international law, focusing in the analysis of the current nature of public policy. Its main objective is to analyze both national public policy and international public policy, considering if both are excluding or converging concepts. Such approach is developed through a metaphorical interpretation of the connection between the concept of public order and the roman divinity Janos mythos. Initially, an analysis is made concerning the formulation of the

1 Doutorando em Direito do Comércio Internacional Pela Universidade Federal de Pernambuco (2016) pedrohfb@hotmail.com

2 Graduação em Direito pela Universidade Federal de Pernambuco (1952), Doutorado em Direito pela Universidade Federal de Pernambuco (1954). Atualmente é professor titular da Universidade Federal de Pernambuco. Tem experiência na área de Direito, com ênfase em Direito Internacional Privado, atuando principalmente nos seguintes temas: Direito Internacional Privado, Legislação sobre estrangeiro e principios aplicáveis, Direito Internacional. Líder do grupo de pesquisa "Integração regional, globalização e Direito Internacional". Url Lattes: http://buscatextual.cnpq.br/buscatextual/visualizacv.do?id=K4790872T5.
\end{abstract}


$104 \mid$ InterAção

concept of national public order in a legal-historic scope, considering legal definitions brought by international and national rules. In sequence, treats about the possibility of conceptualization of a international public order and which would be the sources of such. This study points toward conclusions in the sense of the need of interpretations that ensure that both modalities of public order coexist and that respect the private international law and national law.

Keywords: Private International Law. National public policy. International public policy. Janus. UNCITRAL.

\section{INTRODUÇÃO}

Jano (do latim Janus ou Ianus) foi o deus romano das mudanças e transições. A divindade era representada com duas faces viradas para direções opostas, as quais simbolizavam os términos e os começos, o passado e o futuro, o dualismo relativo de todas as coisas. Sendo considerado uma das divindades mais importantes do arcaico panteão romano, era muitas vezes equiparado ao deus Júpiter.

Elemento interessante da dualidade passado/presente verificada na referida divindade é a coexistência de ambos em uma mesma entidade. Tradicionalmente, a face de um velho era utilizada para representar o passado, enquanto, em plano oposto, a face de um jovem representaria o futuro. Como ambas as faces compõem um mesmo ser, convivendo simultaneamente, a noção de tempo pretérito e futuro manifesta-se para os romanos nesse sentido de maneira convoluta, apontando em direções distintas, porém intimamente associados.

A coexistência de institutos que apontam em sentidos distintos, porém existem simultaneamente pode ser verificado também em alguns institutos do Direito. Certas vezes, interpretações que, numa primeira análise, apontam em 
$105 \mid$ InterAção

sentidos antagônicos podem na realidade indicar uma profunda convergência, revelando que, mais do que opostos, em realidade são partes de um mesmo ente.

Essa dualidade entrelaçada pode ser verificada nas discussões acerca da aplicação da ordem pública no Direito Internacional Privado. O instituto da ordem pública, princípio de grande importância para o referido Direito, é um elemento de profundos debates acerca da possibilidade de aplicação ou não de regras estrangeiras em ordenamentos jurídicos internos. Por se tratar de um conceito vago, porém de importantes aplicações, diversos aplicadores do direito debruçaram-se sobre a mesma para tentar traçar seus limites e hipóteses de incidência. Ainda assim, é sabido que há uma grande dose de abstração na aplicação da ordem pública por parte dos ordenamentos jurídicos nacionais.

O caráter abstrato de certos institutos do Direito, como é o caso da ordem pública, apesar de ser muitas vezes necessário para garantir sua correta aplicação em situações concretas, pode conduzir a situações de insegurança. A insegurança é especialmente danosa no Direito Internacional Privado por ele muitas vezes ser aplicado para disciplinar atividades econômicas, as quais necessitam do máximo de previsibilidade e confiança.

Não por acaso, muito do disciplinamento jurídico dessas atividades realizado pelo Direito Internacional Privado busca permitir que as interações econômicas, principalmente de comércio internacional, ocorram dentro de um certo grau de previsibilidade para as partes. Assim, é necessário que o disciplinamento da matéria pelo Direito Internacional Privado ocorra de maneira a garantir tal convergência, conforme analisa a Profa. Eugênia Barza:

O disciplinamento de atividades econômicas implica na normatização das relações de comércio exterior, fruto de convergência política e presente em acordos internacionais. A influência exterior se faz presente, o intercâmbio propicia questionamentos sobre lei aplicável dentre as possíveis provenientes de ordens jurídicas diferentes. (BARZA, 2013, p. 27) 
106 | InterAção

A aplicação da lei estrangeira para certos casos, contudo, mesmo que definida de maneira adequada entre os países, pode ser obstaculizada por meio da ordem pública. O referido princípio garante que normas e institutos estrangeiros que sejam ofensivos ao ordenamento jurídico interno não sejam aplicados no caso concreto, sendo verdadeiro elemento negativo à aplicação do Direito Internacional Privado. Verifica-se, portanto, o poder que a ordem pública possui na presente matéria, porém seus limites via de regra são fracamente traçados.

No âmbito do continente americano, o Código de Direito Internacional Privado, amplamente conhecido como Código de Bustamante, internalizado pelo Direito Brasileiro por meio do Decreto n 18.871 de 1929, é um dos principais referenciais para aplicação do Direito Internacional Privado na região, tendo sido amplamente internalizado. O referido diploma aponta inúmeras vezes a ordem pública internacional como elemento de grande importância para definir, limitar ou até mesmo impedir a aplicação do Direito Internacional Privado em um dado Estado, porém deixa de definir de forma específica o que constituiria a ordem pública.

Mais que isso, a própria definição de onde se deve buscar a ordem pública para aplicação no Direito Internacional Privado é convoluta. Numa visão tradicional, verifica-se que o instituto decorre de uma manifestação eminentemente nacional de cada Estado, devendo cada país definir que valores fundamentais não poderiam ser ofendidos por normas jurídicas estrangeiras. Há, contudo, uma crescente importância da manifestação internacional do instituto, à medida que cada vez mais se fala em princípios internacionais a serem aplicados no Direito Internacional Privado, os quais não necessariamente derivam de um ordenamento Estatal. 
107 InterAção

A diversidade de opções de onde buscar os fundamentos para a ordem pública tem sido objeto de debate na doutrina, com importantes opiniões ressaltando a importância de cada face, nacional e internacional, da ordem pública. É possível, todavia, que ambas as faces componham uma mesma entidade, a qual apenas pode ser compreendida caso analisada como um todo.

Assim como a divindade mitológica Jano, a ordem pública talvez apresente duas faces que coexistam em um mesmo ser, apontando em direções diversas, verdade, porém integrando-se numa figura maior. É nesse sentido que se pretende analisar as faces nacional e internacional da ordem pública no Direito Internacional Privado, verificando de forma sintética a aplicação de cada uma para por fim fundi-las em uma mesma figura, analisando se é possível observar também não apenas a semelhança ao deus Jano em seu caráter dual, mas também no aspecto da representação de uma ideia de transição presente nessa divindade.

\section{A FACE NACIONAL DA ORDEM PÚBLICA}

A ordem pública, apesar de sua patente importância para a aplicação do direito internacional privado e a regulação dos contratos internacionais, é típico exemplo de um conceito jurídico indeterminado, tendo sua acepção variado não apenas no tempo, mas entre os distintos ordenamentos jurídicos.

A formulação da moderna teoria do princípio da ordem pública é habitualmente atribuída a Savigny, o qual defendeu a possibilidade das nações recusarem determinados institutos jurídicos estrangeiros claramente ofensivos aos valores do ordenamento jurídico nacional. Dessa forma, institutos como a escravidão e a poligamia, institutos há muito proibidos nos diversos 
108 InterAção

ordenamentos jurídicos ocidentais, eram afastadas por países que não reconheciam tais práticas como válidas ou reconhecíveis pelo Direito.

Nessa concepção clássica, verifica-se que a ordem pública surge no direito internacional privado como uma capacidade negativa, uma prerrogativa para não aplicação da norma estrangeira que, mesmo que considerada válida no ordenamento jurídico em que se originou, colide com os valores fundamentais nacionais. Mais que isso, é importante notar que o referencial para a definição da ordem pública é o direito interno de cada país, portanto é um instituto que deriva do que cada ordenamento jurídico considera como atentatório ou não a seus valores primordiais. Conforme aponta Dolinger:

O princípio da ordem pública em direito internacional privado desempenha um papel negativo; os tribunais a ele recorrem ou para recusar o conhecimento de uma ação (experiência norteamericana) ou rejeitar a aplicabilidade da lei estrangeira indicada pela norma de direito internacional privado (experiência européia e latino-americana). Seu efeito é impeditivo, ao repelir a norma de direito material indicado pela regra de conexão do DIP. A característica essencial do princípio de ordem pública no DIP é a sua natureza nacional, em defesa de interesses internos contra leis estrangeira inassimiláveis, o que tem ocasionado um certo exagero na sua utilização.(DOLINGER, 1986, p. 208)

Há, portanto, um caráter eminentemente nacional na aplicação da ordem pública no direito internacional privado. Cabe ao aplicador do direito em cada Estado interpretar quais o valores fundamentais abrangidos pela ordem pública em seu país e considerar se a proteção aos mesmos justifica o afastamento de normas ou institutos estrangeiros.

Os mais diversos setores do Direito Internacional Privado podem ser afetado por essa noção de ordem pública. Para além da utilização desse instituto para negar a homologação de decisão estrangeira, exemplo previsto no artigo 
109 | InterAção

963, VI, do Código de Processo Civil brasileiro³, é possível a declaração de nulidade de certas cláusulas de contratos internacionais ou mesmo a recusa do reconhecimento ou da execução de sentença arbitral internacional. Tal hipótese é expressamente prevista na Lei Modelo da UNCITRAL ${ }^{4}$ em seu artigo 36, 1, b, ii, que define, ipsis litteris:

Artigo 36. ${ }^{\circ}$

Fundamentos de recusa do reconhecimento ou da execução 1 - O reconhecimento ou a execução de uma sentença arbitral, independentemente do país em que tenha sido proferida, só pode ser recusado:

(b) O tribunal constatar:

ii. Que o reconhecimento ou a execução da sentença contrariam a ordem pública do presente Estado.

A amplitude com que a ordem pública pode ser aplicada e o alto grau de abstração que o aplicador do direito interno possui em considerar quais institutos podem ser atentatórios a ela contribuiu para que diversos doutrinadores criticassem a utilização indiscriminada da ordem pública.

Desse modo, observa-se a manifestação da ordem pública em seu aspecto tradicional como uma importante entidade para o Direito Internacional Privado. Assim como a face de Jano que se volta ao passado, o instituto está na origem da consolidação desse Direito em seu aspecto moderno, perpetuando sua importância não apenas no passado, mas tendo efeitos também no presente. Não é possível se falar em ordem pública, portanto, sem considerar sua manifestação como decorrência do direito interno de cada país e da liberdade dos aplicadores do direito em buscar quais seus limites e suas aplicações.

É sabido, contudo, que a liberdade das partes em contratar e definir o direito aplicável a suas relações são princípios basilares do Direito Internacional

\footnotetext{
${ }^{3}$ Art. 963 . Constituem requisitos indispensáveis à homologação da decisão: $\mathrm{VI}$ - não conter manifesta ofensa à ordem pública.

${ }^{4}$ Lei Modelo da UNCITRAL sobre Arbitragem Comercial Internacional - Disponível em: http://s.conjur.com.br/dl/leimodelo-arbitragem-elaborada.pdf
} 
$110 \mid$ InterAção

Privado, de modo que o princípio da ordem pública não deve ser invocado de maneira temerária arbitrariamente prejudicando tais liberdades. Nesse sentido, autores como Dolinger defendem a possibilidade de aplicação de sentenças estrangeiras parcialmente, preservando os pontos que não forem atentatórias à ordem pública, de modo a garantir que a ordem pública restrinja, porém não obstaculize por completo a aplicação do Direito Internacional Privado.

A multitude de ordenamentos jurídicos nacionais e o alto grau de liberdade que cada um possui para interpretar o que é atentatório a sua ordem pública de seu Estado levou a diversos questionamentos sobre a possibilidade de alguma previsibilidade acerca da aplicação do instituto no direito internacional.

Assim como verifica-se ter ocorrido nas últimas décadas um esforço de padronização (quando não possível de uniformização) de normas de Direito Internacional Privado a serem adotadas em cada Estado, observa-se também o surgimento de tentativas de esboçar uma noção de ordem pública internacional, a qual não estaria adstrita a ordenamentos jurídicos nacionais individuais.

\section{A FACE INTERNACIONAL DA ORDEM PÚBLICA}

O Direito Internacional Privado é, fundamentalmente, um direito interno, formulado por cada país para definir a interação com elementos estrangeiros em seu direito, sejam decisões estrangeiras, sentenças arbitrais internacionais, contratos internacionais, dentre outros. Desse modo, a aplicação ou não desse direito passa pela interpretação de normas e princípios internos, os quais podem variar sensivelmente em cada Estado.

O Direito, contudo, não pode ser mera manifestação abstrata desatrelada da realidade material. É sabido que um dos principais aspectos a ser considerado 
111 InterAção

nas interações transnacionais é o econômico, muitas vezes representado por meio de transações comerciais, e uma das grandes preocupações de tais transações é a segurança. De tal sorte, há uma preocupação cada vez mais presente no Direito Internacional Privado em preservar a garantia do pacta sunt servanda, permitindo que as negociações internacionais ocorram de forma segura e conforme acordadas pelas partes integrantes.

Nesse sentido, a normatização do Direito Internacional Privado nas últimas décadas verificou uma grande preocupação em uniformizar as normas desse direito nos distintos ordenamentos jurídicos. Inicialmente no continente americano por meio das diversas Conferências Pan-Americanas e mais recentemente através de Organizações Internacional como a UNCITRAL (Comissão das Nações Unidas para o Direito Comercial Internacional) e o UNIDROIT (Instituto Internacional para a Unificação do Direito Privado) observa-se a tentativa de formulação de normas comuns em matéria de Direito Internacional Privado para os diversos países.

Seja por meio de códigos ou leis-modelos, há um esforço claro de harmonização legislativa no Direito Internacional Privado. Assim, há um esforço para que não apenas as normas em sentido estrito sejam semelhantes, mas que também haja uma harmonização na aplicação dos diversos institutos jurídicos que permeiam a matéria.

Verifica-se, nas últimas décadas, uma crescente valorização dos princípios no Direito, corrente esta que tem afetado também o Direito Internacional. A ascensão da relevância dos princípios na esfera internacional foi observada com grande relevância com o crescimento da importância dos mesmos nas discussões acerca de Direitos Humanos, porém é possível observar sua presença em diversos outros ramos. 
112 InterAção

O Direito Internacional Privado não foi exceção. Cada vez mais doutrinadores e aplicadores do direito se têm utilizado dos princípios para balizar a aplicação do Direito Internacional Privado, muitas vezes tendo de aplicar teorias de colisões de princípios e ponderação de valores para buscar decisões adequadas.

Em meio a esse cenário, a interpretação acerca da ordem pública também sofreu impactos. Tradicionalmente vista como um elemento nacional, passou-se a discutir a possibilidade de se buscar valores fundamentais capazes de afastar elementos de ordenamentos estrangeiros não apenas dentro de cada Estado, mas em princípios basilares protegidos pela sociedade internacional. O caráter não adstrito ao âmbito nacional dessa ordem pública levou alguns autores inclusive a defender a definição da mesma como uma ordem pública mundial, comum a todos os povos e Estados, apesar de essa terminologia ainda ser bastante debatida hodiernamente.

Assim, questões como a proteção à princípios ditos como fundamentais pelo Direito Internacional tem contribuído para a formação de uma ordem pública internacional. Exemplos como a não comercialização de produtos resultado de trabalho escravo ou a crescente preocupação com a negociação de produtos que causem menos impacto ao meio ambiente podem apontar para o surgimento de valores fundamentais da sociedade internacional que deverão ser observados por qualquer Estado quando da sua participação no comércio internacional.

A ordem pública internacional, portanto, ainda é um instituto em formação, que aponta para algo que possa surgir e se consolidar de maneira mais definitiva no futuro. É possível fazer um paralelo da mesma com a face de Jano voltada para o futuro, que aponta para algo que ainda está por vir, porém já se faz sentir no tempo presente. 
113 | InterAção

Há, contudo, um grande debate acerca de onde se deve buscar o fundamento para a ordem pública internacional. Diferentemente da ordem pública nacional, a qual deve ser buscada em cada ordenamento jurídico nacional, não há na manifestação internacional da ordem pública um ente bem definido, à semelhança do Estado, capaz de servir como fundamento basilar.

Desse modo, há argumentos que definem os Direitos Humanos como fonte para buscar a ordem pública internacional, como princípios básicos que deveriam ser garantidos a qualquer ser humano. Especificamente tratando de Direito Internacional Privado, parte da doutrina aponta a Lex Mercatoria moderna, fonte essa inclusive passível de profundos debates acerca de sua manifestação e limites, como fonte normativa para buscar a ordem pública internacional em matéria de comércio internacional. Outros definem que as normas acerca da arbitragem internacional, uma das mais intensas manifestações do Direito Internacional Privado, é que deveriam conter as definições e aplicações da ordem pública internacional.

Independentemente de qual fundamento seja buscado, é certo que qualquer fonte do Direito Internacional a ser aplicada para fundamentar a ordem pública não se aplica da mesma forma que a ordem pública presente nos ordenamentos jurídicos nacionais. Há, portanto, que se analisar se a ordem pública internacional deveria ser algo também a ser analisado pelo aplicador do direito quando da incidência da norma estrangeira.

Não apenas isto, a presença de uma ordem pública internacional tem trazido o questionamento da necessidade de perpetuação da ordem pública no aspecto nacional, a qual muitas vezes é aplicada de maneira não moderada. Com a presença de uma ordem pública única, internacional ou mundial, seria possível a tão almejada uniformização do instituto, trazendo maior previsibilidade às negociações internacionais. 
$114 \mid$ InterAção

Há, contudo, que se considerar que a ordem pública é resultado das formulações de um ordenamento jurídico e ainda é difícil se considerar a existência, ao menos nos aspectos tradicionais, de um ordenamento jurídico internacional uniforme. Assim, valores fundamentais de cada nação ainda podem variar sensivelmente, não sendo possível se definir uma ordem pública única a ser aceita por todos sem que isso implique na limitação de garantias de certos grupos.

Do mesmo modo que não é possível compreender a divindade Jano sem considerar ambas suas faces, também não é possível se falar em ordem pública hodiernamente sem considerar suas distintas acepções coexistindo simultaneamente.

\section{CONSIDERAÇÕES FINAIS: AS DUAS FACES DA DIVINDADE}

Jano foi o deus romano não apenas do passado e futuro, representado por suas duas faces observando em direções opostas, mas também das mudanças e transições. É compreensível a presença também do aspecto de transitoriedade nessa divindade quando se considera que a ideia de passado e futuro confundem-se em um mesmo ponto em um mesmo ser, dando a ideia de algo que surge em um momento pretérito, porém perpetua-se rumo ao futuro.

A transitoriedade verifica-se também nas duas faces da ordem pública. A formulação tradicional do instituto foi feita em um período logo após a consolidação de um Estado que foi um dos berços desse instituto jurídico, a Alemanha e o direito germânico, época em que havia uma grande valorização da figura do Estado nacional e concentração de suas atribuições. Nesse sentido, o conceito clássico de ordem pública está profundamente atrelada à noção de 
115 | InterAção

soberania e poder do Estado-Nação, noção essa que ainda se perpetua na atualidade.

Por outro lado, as mudanças no cenário internacional do pós guerra e a crescente internacionalização de diversos temas tradicionalmente exclusivos dos direitos internos contribuiu para que o surgimento da ideia de ordem pública internacional estivesse voltada para uma ideia ainda em formação, a qual talvez irá consolidar-se em um cenário futuro. É certo que a ordem pública internacional já se faz presente não apenas no campo da abstração, porém sua consolidação, tal qual a ordem pública nacional, ainda é prematura.

Verifica-se, portanto, que ambas as ordens públicas coexistem no momento presente, influenciando-se mutuamente e não podendo ser interpretadas uma à exclusão da outra. $\mathrm{O}$ caráter de direito interno ainda é marcante no Direito Internacional Privado, porém cada vez mais é possível observar a presença de elementos internacionais em sua formulação e aplicação, evento este que não deixa de se fazer presente na aplicação da ordem pública.

O elemento da transitoriedade também pode ser observado nessa análise. Não seria possível o surgimento da ordem pública internacional sem previamente ter sido consolidada a noção de ordem pública nacional, assim, uma face pode ser vista como uma transição da outra. Como qualquer elemento transitório, é difícil definir por marcos claros qual o fim de um elemento e o início do outro, de modo que muitas vezes não há uma definição incontestável de qual face está sendo aplicada quando se aplica a ordem pública, a nacional ou internacional.

Em tal situação, um aplicador do direito ao invocar a ordem pública para afastar a aplicação de determinada norma estrangeira não necessariamente reconhece qual aspecto da ordem pública está utilizando na situação concreta, podendo o fundamento transitar entre a esfera nacional e internacional. Essa 
116 | InterAção

incerteza é inerente à própria natureza indeterminada da ordem pública, a qual não é taxativamente definida em nenhuma de suas faces.

A definição da ordem pública nacional como a face do passado e a internacional como a do futuro não implica, necessariamente, em definir que uma irá se extinguir para a ascensão da outra. Um rumo que pode ser cogitado, contudo, é que a crescente internacionalização de temas tradicionalmente tratados em bases soberanas contribuirá para a crescente valorização da ordem pública internacional, em detrimento de sua manifestação em bases exclusivamente nacionais. Ainda assim, essa ideia de transição deve ser interpretada de maneira semelhante à imagem do deus Jano, com ambas as faces coexistindo em um mesmo momento.

Qualquer transição, conforme é sabido, implica em mudanças, na qual se verifica a coexistência do antigo e do novo. Uma face não deixa de existir para que a outra possa surgir, do mesmo modo, um instituto não necessariamente deixa de ser válido e aplicável devido ao surgimento de outro.

A dualidade da noção de ordem pública é uma realidade, tendo cada um de seus aspectos características próprias, em grande parte decorrentes dos momentos em que cada uma foi formulada, que, apesar de as distinguirem, as integram em uma mesma noção. Assim como os romanos compreendiam sua divindade Jano, é necessário compreender a coexistência dual do aspecto nacional e internacional da ordem pública para entender toda sua importância no Direito Internacional Privado.

Não é tarefa fácil compreender uma divindade mitológica em todas suas acepções, ainda mais quando a mesma representa aspectos que, numa primeira análise, podem ser contraditórios. Nesse mesmo sentido, também não é fácil compreender um conceito jurídico indeterminado que, assim como o mito, passa por transformações no tempo e pode ter diferentes significados em diferentes 
117 InterAção

ordenamentos. Ainda assim, tal qual cabia ao sacerdotes interpretar os sinais divinos e agradar aos deuses, cabe ao aplicador do direito compreender os institutos jurídicos de grande relevância como a ordem pública e buscar aplicálos de forma adequada, garantindo a consolidação do direito.

\section{REFERÊNCIAS}

BARZA, Eugênia Cristina Nilsen Ribeiro. A idéia de Comércio Internacional e suas implicações para o Direito Internacional. Caderno de Relações Internacionais, Faculdade Damas, v. 4, n. 6, 2013. Disponível em: http:// www.faculdadedamas.edu.br/revista/index.php/relacoesinternacionai s.

DOLINGER, Jacob. Ordem pública mundial : ordem pública verdadeiramente internacional no direito internacional privado, Revista de informação legislativa, v. 23, n. 90 (abr./jun. 1986). Disponível em http:/ / www2.senado.leg.br/bdsf/handle/id/181712.

ESTEVADEORDAL, A., SUOMINEN, K., and TEH, R. (eds). Regional Rules in the Global Trading System, IDB, WTO, 2009.

FURTADO, Paulo, et alii. Lei da Arbitragem Comentada. São Paulo: Saraiva, 1997.

H.H. Scullard, Festivals and Ceremonies of the Roman Republic. Thames and Hudson, London, Cornell University Press, 1981.

Lei Modelo da UNCITRAL Sobre Arbitragem Comercial Internacional Disponível em: http://s.conjur.com.br/dl/lei-modelo-arbitragemelaborada.pdf

PETERSON, Niels. How Rational is International Law?. in The European Journal of International Law. Vol. 20 no. 4 (C) EJIL, 2010.

THORSTENSEN, Vera; RAMOS, Daniel; MULLER, Carolina e NAKAGAWA, Adriane. Sistemas de regulação do comércio internacional em confronto: o marco dos Estados e o marco das transnacionais. Revista Política Externa, HMG Editora, v. 21 n 4 - Abr/Mai/Jun 2013. 
$118 \mid$ InterAção

VARELLA, M. D.. A crescente complexidade do sistema jurídico

internacional. in Revista de Informação Legislativa. Brasília a. 42 n. 167 jul./set, 2005. 